INTERNATIONAL FOOD

POLICY RESEARCH INSTITUTE

sustainable solutions for ending hunger and poverty

IFPRI ${ }^{\circledR} \quad$ Supported by the CGIAR

IFPRI Discussion Paper 01008

July 2010

\title{
Livestock Development Planning in Uganda: Identification of Areas of Opportunity and Challenge
}

\author{
Todd Benson \\ Samuel Mugarura
}

Development Strategy and Governance Division 


\section{INTERNATIONAL FOOD POLICY RESEARCH INSTITUTE}

The International Food Policy Research Institute (IFPRI) was established in 1975. IFPRI is one of 15 agricultural research centers that receive principal funding from governments, private foundations, and international and regional organizations, most of which are members of the Consultative Group on International Agricultural Research (CGIAR).

\section{PARTNERS AND CONTRIBUTORS}

IFPRI gratefully acknowledges the generous unrestricted funding from Australia, Canada, China, Denmark, Finland, France, Germany, India, Ireland, Italy, Japan, the Netherlands, Norway, the Philippines, South Africa, Sweden, Switzerland, the United Kingdom, the United States, and the World Bank.

\section{AUTHORS}

Todd Benson, International Food Policy Research Institute

Senior Research Fellow, Development Strategy and Governance Division

Kampala, Uganda

T.Benson@cgiar.org

Samuel Mugarura

Secretariat for the Plan for Modernisation of Agriculture

Kampala, Uganda

\footnotetext{
Notice

${ }^{1}$ Effective January 2007, the Discussion Paper series within each division and the Director General's Office of IFPRI were merged into one IFPRI-wide Discussion Paper series. The new series begins with number 00689, reflecting the prior publication of 688 discussion papers within the dispersed series. The earlier series are available on IFPRI's website at www.ifpri.org/pubs/otherpubs.htm\#dp.

2 IFPRI Discussion Papers contain preliminary material and research results. They have not been subject to formal external reviews managed by IFPRl's Publications Review Committee but have been reviewed by at least one internal and/or external reviewer. They are circulated in order to stimulate discussion and critical comment.
}

Copyright 2010 International Food Policy Research Institute. All rights reserved. Sections of this material may be reproduced for personal and not-for-profit use without the express written permission of but with acknowledgment to IFPRI. To reproduce the material contained herein for profit or commercial use requires express written permission. To obtain permission, contact the Communications Division at ifpri-copyright@cgiar.org. 


\section{Contents}

Abstract vi vi

1. Introduction 1

2. Analytical Methods 3

3. Data

4. Results 9

5. Discussion 14

References $\quad 15$ 


\section{List of Tables}

1. Livestock stocking density model variables: Descriptive statistics

2. Results of spatial error maximum-likelihood estimation model of the livestock stocking density in the sub-counties of Uganda 


\section{List of Figures}

1. Uganda 2008 National Livestock Census results: Percentage of households rearing livestock, by subcounty

2. Maps of variables used in model (1 of 2)

3. Maps of variables used in model ( 2 of 2)

4. Maps of the observed and predicted livestock stocking rates for the sub-counties of Uganda

5. Relative residual from model estimate of livestock stocking density for sub-counties in Uganda compared to observed, in percent; dot map of distribution of tropical livestock units (TLUs) in Uganda 12 


\begin{abstract}
Livestock are an important element of the livelihoods of many Ugandan households, and considerable efforts at economic development by the government of Uganda have focused on the livestock sector. However, these development efforts have suffered due to a lack of detailed data on the distribution of livestock in Uganda to guide the targeting of such programs. In this paper we use data from the 2008 National Livestock Census to develop a better understanding of where in Uganda there might be potential for significant investment to intensify the production of livestock and, conversely, where there are important challenges, such as conflicts between human populations and livestock that need to be addressed. This analysis is done by developing a quantitative model to predict mean livestock stocking rates at sub-county level $(n=929)$ that uses population density, agroecological factors, and market access as explanatory variables. A mapping of the model residuals approach is then used to identify areas in Uganda that are relatively understocked and those that are potentially overstocked. This information is then used to suggest approaches to livestock development in both types of areas.
\end{abstract}

Keywords: Uganda, livestock, spatial analysis, development planning 


\section{INTRODUCTION}

Livestock is an essential agricultural resource for Uganda. Uganda's populations of cattle, goats, and poultry are among the highest among African countries - generally in the top quintile. Nomadic pastoralism constitutes the principal livelihood for many households in the northeastern part of Uganda. The landscape of the so-called cattle belt, stretching across the middle of Uganda from the base of the highlands in southwestern Uganda through the area around Lake Kyoga to northeastern Uganda, is characterized by extensive cattle-dominated farming systems. Intensive livestock production is common in areas with higher population densities, with dairy cattle ownership being an important characteristic of economically progressive farmers in these zones. Investment in intensive poultry production, both layers and broilers, has over the past 15 years become increasingly common in periurban areas of Uganda. Seventy percent of Ugandan households are engaged in some form of livestock rearing (MAAIF and UBOS 2009).

Although crop agriculture generally receives more attention than livestock in the development programs of the government of Uganda, livestock is part of the vision of Uganda's leaders for economic development and poverty reduction. Livestock is given attention in Uganda's National Development Plan (2010/11-2014/15), which seeks annual growth of 5.4 percent in the sector, up from an average of 3.0 percent in recent years (NPA 2010). Beef and dairy cattle and poultry are identified as strategic agricultural commodities for the country that are to receive increased investment levels for accelerated production. Efforts continue to restrict the distribution of tsetse fly and control trypanosomiasis across Uganda. Since independence, considerable public investments have been made in ranching schemes, veterinary disease control, and livestock markets. However, many of these investments were planned without sufficient understanding of the opportunities for and constraints to livestock development nationally. A principal reason for this has been the lack of good estimates of the distribution of livestock and of the prevalence of livestock ownership across Uganda.

In February 2008 the National Livestock Census was carried out across Uganda. The livestock census - in reality, a large sample survey - involved interviewing approximately 950,000 households in almost all sub-counties across the country concerning their livestock ownership and livestock-related activities. With the publication of the statistical abstract from the livestock census in May 2009 (MAAIF and UBOS 2009), livestock development program designers and implementers now have a significant source of detailed information on livestock to use as evidence to guide their planning activities (see Figure 1). The research presented in this paper is one of the initial attempts to extract from this important new dataset information that will be of use to development planners. ${ }^{1}$

\footnotetext{
${ }^{1}$ Data from the 2008 National Livestock Census was provided by the Ministry of Agriculture, Animal Industry and Fisheries (MAAIF). We are particularly grateful to Mr. George Otim of the Agricultural Planning Department for his support of this analysis.
} 
Figure 1. Uganda 2008 National Livestock Census results: Percentage of households rearing livestock, by sub-county

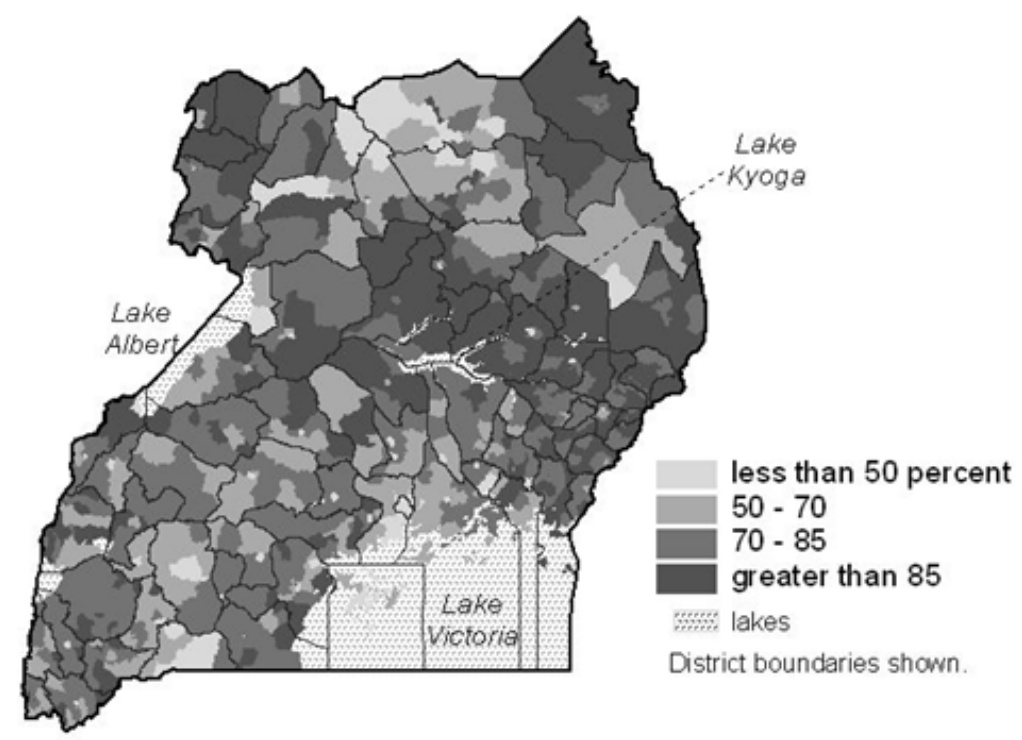

We use data from the 2008 National Livestock Census to investigate where in Uganda there might be potential for significant investment to intensify the production of livestock and, conversely, where there are important challenges, such as conflicts between human populations and livestock, that need to be addressed. This analysis is done by developing a quantitative model to predict mean livestock stocking rates, expressed as tropical livestock units (TLU) per square kilometer, at sub-county level $(n=$ 929) using population density, agroecological factors, and market access as explanatory variables. This model is estimated using a spatial regression technique - a spatial error maximum-likelihood estimation model - that controls for spatial autocorrelation in our dataset. We then use an exploratory data analysis method for spatial data, the mapping of the model residuals, to identify sub-counties whose observed livestock stocking rates are much lower than the model predicts and those whose observed stocking rates are much higher than the model predicts. Those areas where the model predicts much lower stocking rates than are actually found are likely overstocked and are candidate areas to target programs that promote more intensive, land-conserving livestock production methods or even destocking. In contrast, those areas where the model predicts much higher stocking rates than are actually observed are candidate areas for targeting programs aimed at enhancing livestock production through increasing the livestock population there. As this analysis is done at the broad, national scale, further local-level studies will need to be done to confirm the results presented here. However, this study provides initial guidance on areas of opportunity and challenge for livestock development in Uganda. 


\section{ANALYTICAL METHODS}

Two analytical techniques are used in this study: (1) derivation of the quantitative model to predict mean livestock stocking rates and (2) mapping of the residuals from this model.

\section{Modeling Mean Livestock Stocking Rates}

Our predictive model of the mean TLU per square kilometer across 929 sub-counties in Uganda relies upon a small set of explanatory variables: population density, agroecological factors, and market access. ${ }^{2}$ An ordinary least square (OLS) regression procedure would be the standard way to develop such a multivariate model. However, livestock stocking densities in Uganda are strongly positively spatially autocorrelated. That is, the TLU per square kilometer for a particular sub-county is closely correlated with the TLU density of neighboring sub-counties - that is, sub-counties with high TLU densities form spatial clusters, as do sub-counties with low TLU densities. In consequence, one of the underlying assumptions of the OLS regression model, that the error terms for each observation are not correlated with one another, is violated, and the statistical interpretation of the results will be inefficient at best, biased and erroneous at worst (Kennedy 1985).

Consequently, this spatial dependence is usually controlled for by using a spatial regression model that controls for the correlation with neighboring observations in the dependent variable. A variable representing this spatial dependency of the dependent variable, called a spatial lag variable, is inserted into the model as a supplementary explanatory variable. The most common way in which this is done is to use the spatial lag of the dependent variable. In the case presented here, the spatial lag variable for each sub-county in our dataset is the weighted mean of the TLU density for neighboring sub-counties.

The spatial dependence in the regression model can be conceptualized as being manifested in two different ways: as a spatial lag or as a spatial error. For the spatial lag, the spatial dependence can be judged to be a direct effect of the livestock stocking density in neighboring sub-counties on the stocking density in a particular sub-county in question. For the spatial error manifestation, the error term for the model in a particular sub-county is correlated with the model error terms of its neighbors, as might occur due to a missing spatial variable for the model that affects a particular sub-county and its neighbors in a similar manner. If uncorrected for, the implications of the effects of these two manifestations of spatial autocorrelation in an OLS base model differ. Where spatial lag dependence is shown, the estimated coefficients in the OLS model will be both biased and inefficient. In the case of spatial error dependence, the estimates will not be biased, but they will be inefficient, making interpretation of the significance of the results difficult. However, although they result from different interpretations of the spatial processes accounting for the spatial autocorrelation in the model, in practice there is usually very little difference between the two spatial models. In order to choose which one to use, the preferred model is the one with the highest Lagrange multiplier (LM) test value (Anselin 1992; Anselin and Rey 1991).

\section{Mapping of Model Residuals}

A residual for an observation from a quantitative model represents the difference between the observed value $(y)$ and the estimated value from the model $(\hat{y})$ for the dependent variable for that observation, or $y$ $-\hat{y}$. Because the units of analysis for our model are geographic units, the sub-counties of Uganda, we can map the residuals from the model for each sub-county. Such a map portrays the spatial patterns of the degree of correspondence between, on the one hand, the national average expectations for livestock stocking densities in the sub-counties of Uganda based on consideration of population density, agroecological factors, and market access and, on the other hand, the actual stocking densities observed.

\footnotetext{
${ }^{2}$ There likely is endogeneity in our model specification. For example, the livestock population potential of an area could as well be a determinant of human population density there as the reverse. While there are econometric methods to control for this sort of simultaneity between dependent and independent variables, since the objective of this modeling of livestock stocking densities is prediction rather than explanation, they are not employed here.
} 
This method of exploratory spatial data analysis has a relatively long history within quantitative geography, being first described in detail by E.N. Thomas in the early 1960s (Thomas 1960) with refinements to the method developed in the following years (Robinson, Lindberg, and Brinkman 1961; Robinson and Fairbairn 1969). Early adopters of this approach generally mapped residuals from simple OLS regressions. With advances in spatial econometric methods and increased computing power, more recent uses of the technique generally employ spatial regression techniques for model development (for example, Brown 1996).

Residual mapping is most commonly utilized at the data exploration stage of an analysis in order to gain insights into additional variables to include in the analysis; the spatial pattern of the residuals may be reflective of the patterns seen in the spatial distribution of a potential explanatory variable for the dependent variable being modeled. However, a second important use for residual maps is to identify areas that deviate significantly from the expected pattern of the relationship being modeled so that these areas can be the subjects of further study (Thomas 1960). The latter is how we are using the technique in this paper. Having identified where the modeled pattern is not maintained, area-specific factors can be considered to account for the divergence from the model. Moreover, those areas that do not match general trends are likely to be of interest from an applied policy standpoint. This is central to our purpose here: We map the residuals in order to gain insights for the geographic targeting of public programs for livestock development. 


\section{DATA}

The dependent variable for the analysis presented here is the average livestock stocking density per subcounty. This is expressed in mean tropical livestock units (TLU) per square kilometer. A TLU corresponds to 250 kilograms of animal weight and is a standardized measure of all livestock in an area. The total TLUs for an area are computed by taking the sum of the following: 0.7 per head of cattle; 0.1 per sheep or goat; 0.2 per pig; 1.0 per camel; and 0.01 per poultry bird (Jahnke et al. 1988). The TLU for each sub-county was computed from livestock population figures estimated from the 2008 National Livestock Census. The design of the livestock census was such that sub-county livestock population by type can be estimated from the dataset.

Three sets of explanatory variables are used to model the livestock stocking density for the subcounties in our dataset: human population, agroecological factors, and market access.

- Two variables related to human population density are used:

- The population density of each sub-county in 2008 based on population projections done by the Uganda Bureau of Statistics (UBOS) from the 2002 Uganda Population and Housing Census.

- A dummy variable ( 0 or 1$)$ indicating whether or not a sub-county is wholly urban in character. This was determined using the master sampling frame of UBOS, in which the UBOS enumeration areas (EAs) are categorized as urban, mixed, or rural. Sub-counties in which all EAs in the sub-county were classified as urban received a value of 1 for this explanatory variable.

- Eight agroecological variables are used.

- Six of these consist of the percentage of total land area in the sub-county covered by six different land use and land cover types: tropical forest, woodland, bush, grassland, wetland, and farmland. These data were developed by the Africover project of the Food and Agriculture Organization of the United Nations (FAO) through the interpretation of high-resolution satellite imagery (FAO 2003).

- Another agroecological variable used is the median number of months per year with fewer than 50 millimeters of rainfall. This variable was computed from the WorldClim monthly rainfall surfaces, which have a resolution of 30 arc seconds (Hijmans et al. 2005).

- Finally, a dummy variable (0 or 1$)$ indicates whether the majority of the sub-county is likely to have tsetse fly present. This variable was computed from an overlay of the maps for Uganda of predicted areas of suitability for each of three tsetse species prepared for the Programme Against African Trypanosomiasis (FAO 2009).

- A single market access variable was used to explain livestock stocking density. This is the natural $\log (\ln )$ of the mean travel time in hours from each sub-county to the nearest urban center with a population greater than 10,000 persons. This variable was extracted from a travel time surface developed by GIS analysts at the International Food Policy Research Institute (IFPRI) using spatial data on the Uganda road network, land use and land cover, and population centers. The natural log was used so that the distribution of the explanatory variable would more closely approximate a normal distribution.

As noted, the unit of analysis employed here is the sub-county. The sub-county is the second administrative level below the district in Uganda and the second administrative level above the village, which is the most local administrative unit. While there are 958 sub-counties nationally, our dataset contains 929 sub-counties. Twenty-three of the sub-counties that do not feature in our dataset consist of 
some urban sub-counties and some island sub-counties in Lake Victoria where the 2008 National Livestock Census was not conducted. Six sub-counties in the northeastern Karamoja area of Uganda were also dropped from our analysis because the stocking densities for those sub-counties computed from the census data were judged implausibly high for the agroecological conditions and extensive livestock production systems prevalent there. ${ }^{3}$

Basic descriptions of the variables used to construct the model for the 929 sub-counties considered are presented in Table 1. Maps of the spatial distribution of these sub-county variables, except for the urban variable, are presented in Figures 2 and 3.

Table 1. Livestock stocking density model variables: Descriptive statistics

\begin{tabular}{|c|c|c|c|c|c|}
\hline Variable & mean & $\begin{array}{l}\text { standard } \\
\text { deviation }\end{array}$ & $\begin{array}{l}\text { mini- } \\
\text { mum }\end{array}$ & median & maximum \\
\hline $\begin{array}{l}\text { Tropical livestock units (TLUs) per square } \\
\text { kilometer—dependent variable }\end{array}$ & 80.4 & 102.5 & 0.4 & 61.8 & $1,577.2$ \\
\hline Persons per square kilometer & 427.9 & 910.3 & 4.3 & 212.8 & $10,579.8$ \\
\hline Urban sub-county $(0 / 1)$ & 0.10 & 0.30 & 0 & 0 & 1 \\
\hline \multicolumn{6}{|l|}{ Land cover type, percent of sub-county area } \\
\hline Tropical forest & 4.6 & 12.7 & 0.0 & 0.0 & 98.8 \\
\hline Woodland & 8.8 & 16.8 & 0.0 & 0.0 & 89.9 \\
\hline Bush & 2.5 & 9.0 & 0.0 & 0.0 & 79.9 \\
\hline Grassland & 13.8 & 20.0 & 0.0 & 3.8 & 91.3 \\
\hline Wetland & 1.8 & 5.4 & 0.0 & 0.0 & 54.0 \\
\hline Farmland & 65.7 & 31.0 & 0.0 & 75.2 & 100.0 \\
\hline $\begin{array}{l}\text { Tsetse, majority of sub-county likely to have } \\
\text { tsetse fly present }(0 / 1)\end{array}$ & 0.45 & 0.50 & 0 & 0 & 1 \\
\hline $\begin{array}{l}\text { Months per year with less than } 50 \mathrm{~mm} \text { rainfall, } \\
\text { median value for sub-county }\end{array}$ & 1.99 & 1.25 & 0 & 2 & 6 \\
\hline $\begin{array}{l}\text { In (travel time): natural log of hours of travel } \\
\text { time to nearest urban center with population } \\
\text { above } 10,000 \text { persons, mean for sub-county }\end{array}$ & 1.15 & 0.87 & -2.86 & 1.23 & 4.39 \\
\hline$n=929$ sub-counties & & & & & \\
\hline
\end{tabular}

${ }^{3}$ The six sub-counties are Panyangara and Rengen in Kotido district, Karita and Loroo in Nakapiripirit district, and Kalapata and Kaabong in Kaabong district. All had TLUs per square kilometer of above 240 calculated from data of the 2008 National Livestock Census. Independent observers of livestock populations in the northeastern Karamoja region of Uganda also expressed skepticism of some of the livestock census estimates for this area of the country (see Anderson and Robinson 2009, 18). 
Figure 2. Maps of variables used in model (1 of 2)
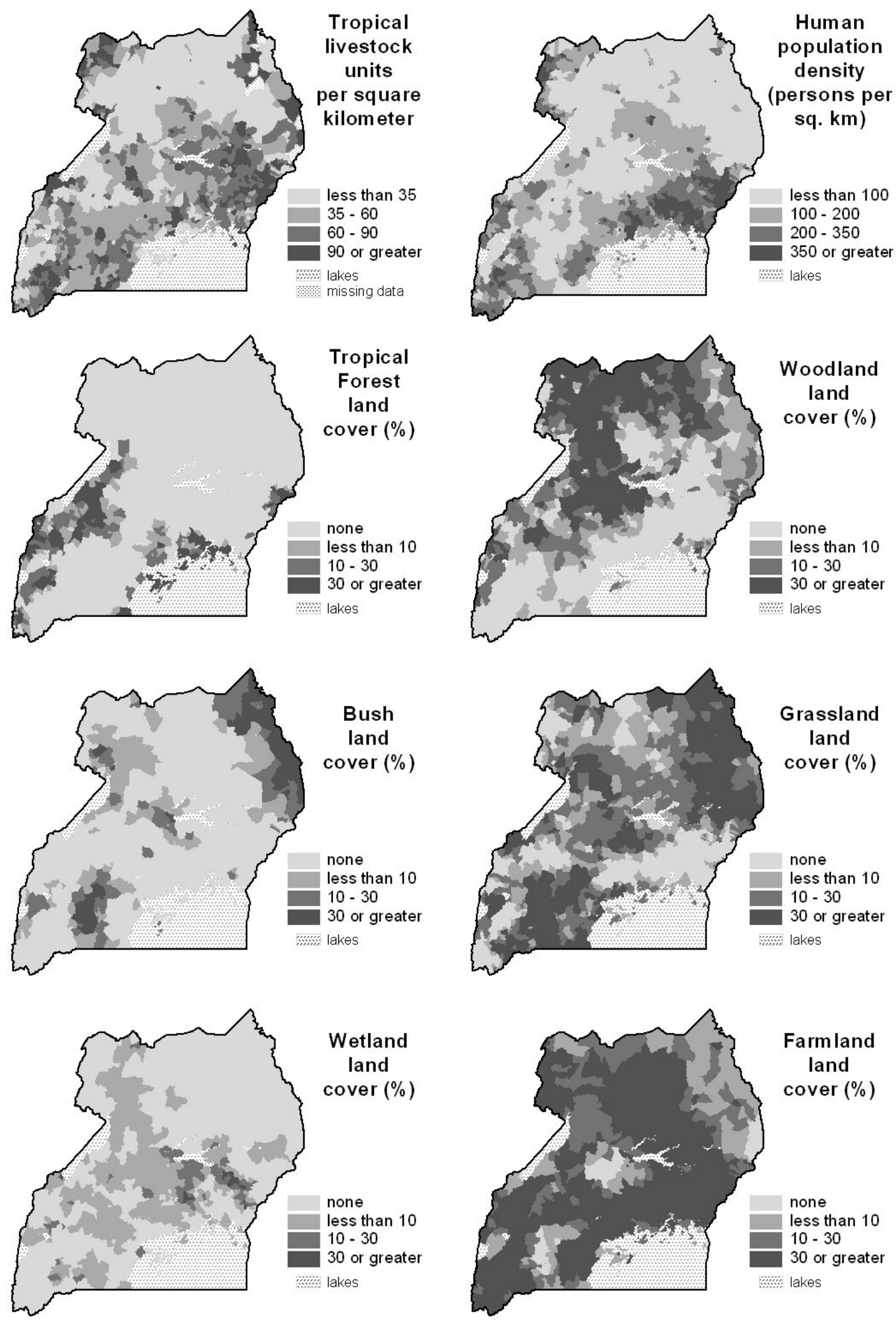
Figure 3. Maps of variables used in model (2 of 2)
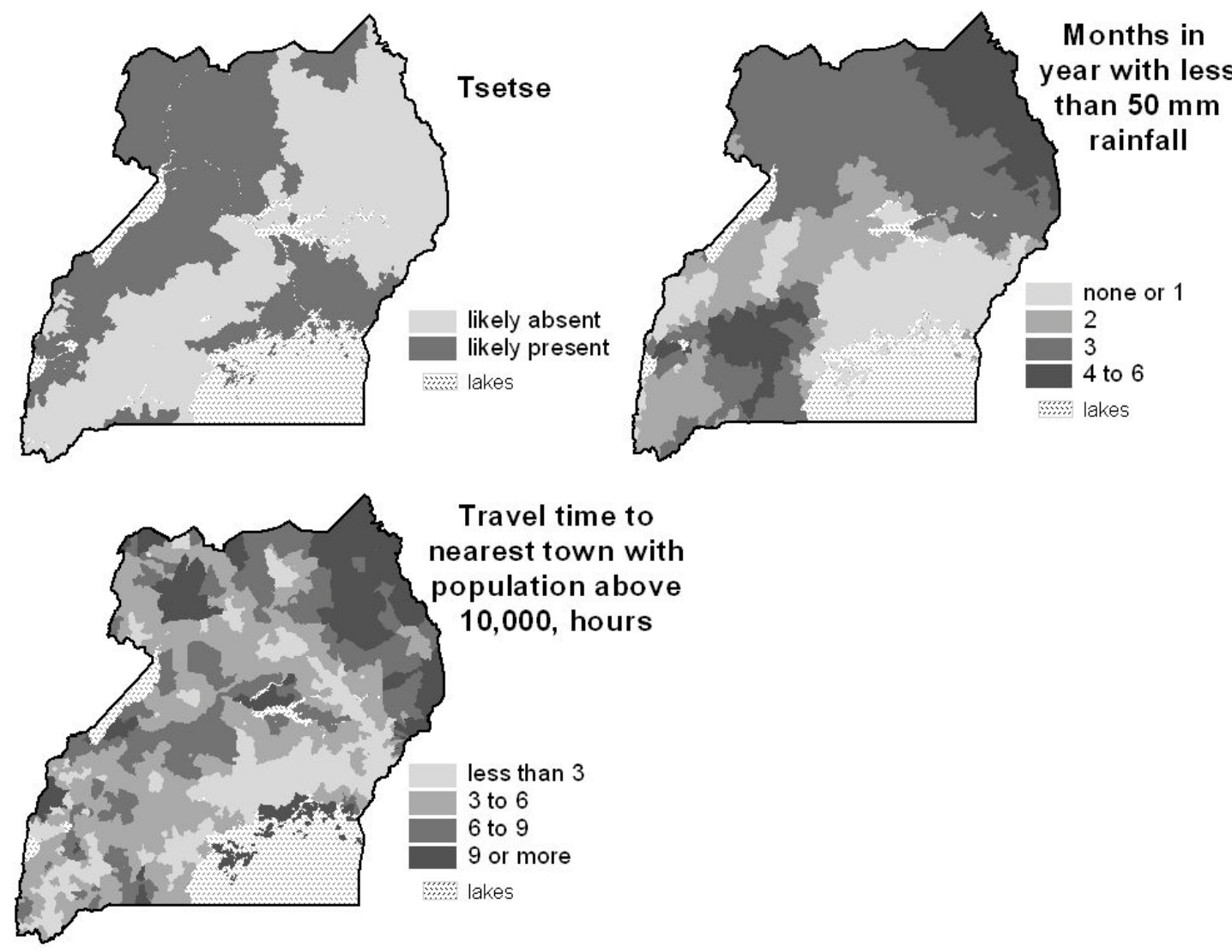


\section{RESULTS}

\section{Regression Results}

The initial step of the modeling analysis involved undertaking a simple OLS regression to determine whether spatial autocorrelation was present in the residuals of the OLS regression of livestock stocking density. The Moran's I statistic provides a measure of the degree of spatial autocorrelation in a variable.

In order to assess spatial autocorrelation, one must first develop a spatial weights matrix to define exactly the "neighborhood" for each sub-county. Several different spatial weighting schemes might be employed that typically are based on distance or contiguity between spatial units or data points (see Lee and Wong 2001, 136-145). To assess spatial autocorrelation in the OLS residuals, a simple first-order queen's spatial weighting matrix was employed: The "neighbors" of any sub-county are defined to be those other sub-counties that share a border or vertex with it.

The Moran's I statistic for the residuals from the OLS model is 0.1173 , which is statistically significant at the $p \leq 0.001$ level. This is strong evidence that the assumption that the error terms for each observation are not correlated, which is necessary to obtain valid results from an OLS regression, does not hold here. There is considerable positive spatial autocorrelation, or spatial clustering, in livestock stocking densities across Uganda: In relatively large portions of the country one finds sub-counties with high livestock stocking rates neighboring areas with similar livestock stocking rates and areas with low rates neighboring other areas with low rates. As such, it would be incorrect to use OLS regression to generate a model of livestock stocking rates at sub-county level for Uganda. A spatial regression model should be used to control for this spatial autocorrelation.

As noted above, the choice of which spatial regression model to use - a spatial error or a spatial lag model - is based on the performance of the respective models. In our analysis, the spatial error model performed slightly better than the spatial lag model.

A spatial weights matrix is also needed for implementing the spatial error maximum-likelihood estimation model. We performed a sensitivity analysis of the spatial autocorrelation in the residuals of the different results obtained from our model using different definitions of neighboring sub-counties. We chose a $20^{\text {th }}$-order queen's spatial weighting matrix. That is, the "neighborhood" consists of sub-counties that share a border or vertex with the sub-county in question plus the neighbors of those sub-counties and their neighbors out to and including 20 concentric rings of sub-counties. It was only by imposing this large neighborhood to generate the spatial lag variable for our analysis - the weighted mean of the TLU density for these neighboring sub-counties - that we eliminated significant spatial autocorrelation in the residuals from the model. Significant spatial error dependence was seen in the model residuals for the lower-order spatial weights matrices.

The results of the spatial error maximum-likelihood estimation model of the livestock stocking density in the sub-counties of Uganda are shown in Table 2. A visual assessment of the results is provided in Figure 4, which compares the maps of the observed livestock stocking densities for Uganda's subcounties from the analysis of the National Livestock Census and that predicted from the spatial error model. 
Table 2. Results of spatial error maximum-likelihood estimation model of the livestock stocking density in the sub-counties of Uganda

\begin{tabular}{lrrc}
\hline Variable & Coefficient & Z-value & Significance \\
\hline Persons per square kilometer & 0.037 & 8.05 & $* * *$ \\
Urban sub-county (0/1) & 114.768 & 8.72 & $* * *$ \\
Tropical forest & 1.299 & 2.90 & $* *$ \\
Woodland & 1.008 & 2.41 & $*$ \\
Bush & 1.551 & 2.96 & $* *$ \\
Grassland & 1.828 & 4.36 & $* * *$ \\
Wetland & 1.919 & 2.84 & $* *$ \\
Farmland & 1.916 & 5.06 & $* * *$ \\
Tsetse (0/1) & -7.390 & -1.18 & $\mathrm{~ns}$ \\
Months with less than 50 mm rainfall & 3.685 & 1.21 & $\mathrm{~ns}$ \\
Travel time to nearest urban center, ln (hrs) & 14.252 & 2.98 & $* *$ \\
Spatial lag variable (mean TLU density for & 0.509 & 2.66 & $* *$ \\
$\quad$ neighboring sub-counties) & & & $* * *$ \\
Constant & -137.987 & -3.48 & $* * *$ \\
\hline
\end{tabular}

Note: Dependent variable: Tropical livestock units per square kilometer

Spatial weight matrix: $20^{\text {th }}$ order queen's; $n=929$ sub-counties

R-squared: 0.275

Spatial error dependence, likelihood ratio test: $2.928 ; p=0.087$

$* * * p \leq 0.001$ level; ${ }^{* *} p \leq 0.01$ level; ${ }^{*} p \leq 0.05$ level; $n s$ : not significant

Figure 4. Maps of the observed and predicted livestock stocking rates for the sub-counties of Uganda

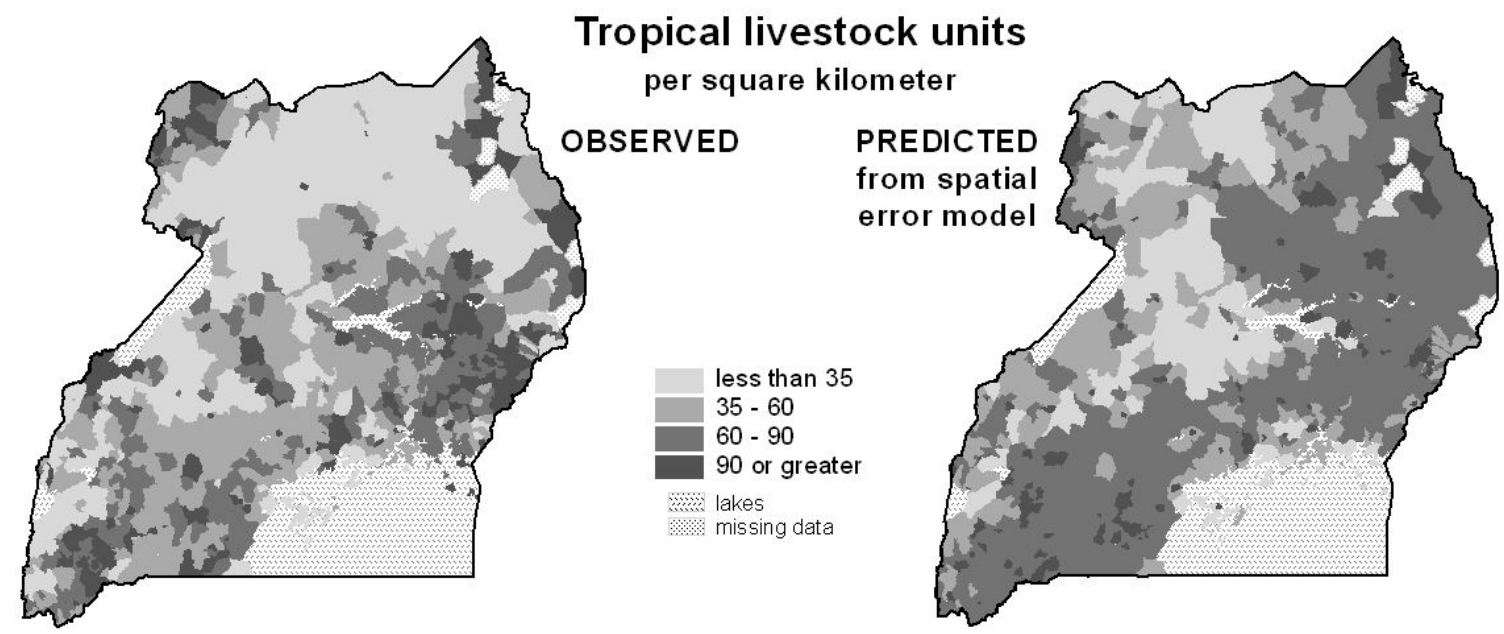

As indicated by the R-squared statistic, 27.5 percent of the variation in livestock stocking density across the sub-counties of Uganda is accounted for by this model. As such, there likely are several other factors, both national and, especially, local, that could be brought into the model to better predict livestock stocking density. However, human population, agroecological factors, and market access provide a useful basic set of factors to explain the distribution and intensity of livestock production. 
Moreover, reasonable explanations can be offered for the specific nature of the relationship between the explanatory variables in our model and livestock stocking densities at sub-county level.

Both of the variables related to human population - population density and whether the subcounty is urban - are positively correlated with livestock stocking density. It may be expected that where there are fewer people there is more space for larger livestock populations. However, most livestock production in Uganda is done in a semi-intensive fashion at household level. More than 70 percent of Ugandan households rear some livestock. Generally households own only a few animals; results of the 2008 National Livestock Census show that the median herd size for the 26 percent of households that own cattle is 3; for the 39 percent that own goats, 3 goats; and for the 50 percent of households that own chickens, 8 birds. As such, large herds and flocks are somewhat exceptional. Consequently, it is to be expected that greater absolute numbers of livestock will be found where there are greater absolute numbers of people.

Even at the extreme of human population densities in Uganda, this relationship is maintained, as indicated by the positive relationship between urban sub-counties and livestock stocking rates. Most of the urban sub-counties are district centers surrounded by rural areas where grazing and fodder is readily available. However, even in Kampala, where urban and suburban land pressures are highest, agriculture, including livestock husbandry, remains an important component of the livelihood strategies urban households pursue (Hooton et al. 2007).

For the agroecological variables, all of the land cover types included in our model have significant positive coefficients, suggesting that livestock-rearing households make use of all available land for pasture and fodder for their animals. Across the land cover types considered, the coefficient for wetlands is highest, likely reflecting the reliable access to fodder throughout the year wetlands provide. Woodlands have the lowest coefficient, which may reflect both less-than-ideal pasture in such landscapes and tsetse-related constraints in some areas, since the spatial distribution of woodlands, particularly in western Uganda, roughly parallels that of tsetse (compare Figures 2 and 3). Given the common mixed livestock and cropping farming systems of Uganda, it is expected that areas with extensive tracts of farmland will be associated with higher livestock densities, and this is reflected in the highly significant positive association between the proportion of the sub-county land that is under farmland and the livestock stocking density for the sub-county.

For the other agroecological variables, the tsetse variable was not statistically significant. This may reflect the success of efforts to control trypanosomiasis in livestock across the country in general. Although our expectation was that livestock husbandry would be associated with areas of Uganda that have longer dry spells, since, relative to crops, livestock husbandry would be expected to be a more appropriate agricultural use in these areas, the results of our model show that there is no significant association between these drier lands and livestock stocking densities, all other things being equal.

The travel time to urban centers variable, which serves as a proxy for market access, somewhat surprisingly has a positive coefficient - the further away an area is from an urban center, the greater the livestock stocking rates observed. Much livestock production in Uganda, as with most agricultural activities, is done principally with subsistence rather than commercial objectives. Livestock also is important as a store of wealth for the household. As such, market access should not be a key determinant of livestock stocking rates in Uganda. Moreover, particularly for cattle raised in an extensive manner, larger cattle herds can be expected to be found at greater distances from urban centers simply because away from urban centers there are not as many commercial land uses competing with grazing.

\section{Mapping of Regression Model Residuals}

In order to interpret the spatial pattern of the residual for each sub-county from our model, we convert the actual difference in TLUs between the observed value computed from the 2008 livestock census data and the value estimated from the model into a relative residual (Thomas 1960). This is done by dividing the residual by the observed value and expressing the result as a percent, or $100(y-\hat{y}) / y$. Sub-counties in which the observed livestock stocking density is greater than that estimated by the model will have 
positive relative residuals, while those where the model predicts higher livestock stocking densities than those observed will have negative relative residuals.

The mean relative residual for the 929 sub-counties is -121.7 percent, while the median is -20.9 percent. There are several large negative outliers. The relative residuals for the sub-counties are mapped in Figure 5. This figure also presents a dot map of the distribution of observed TLUs across Uganda, drawn from the 2008 National Livestock Census.

\section{Figure 5. Relative residual from model estimate of livestock stocking density for sub-counties in Uganda compared to observed, in percent; dot map of distribution of tropical livestock units (TLUs) in Uganda}

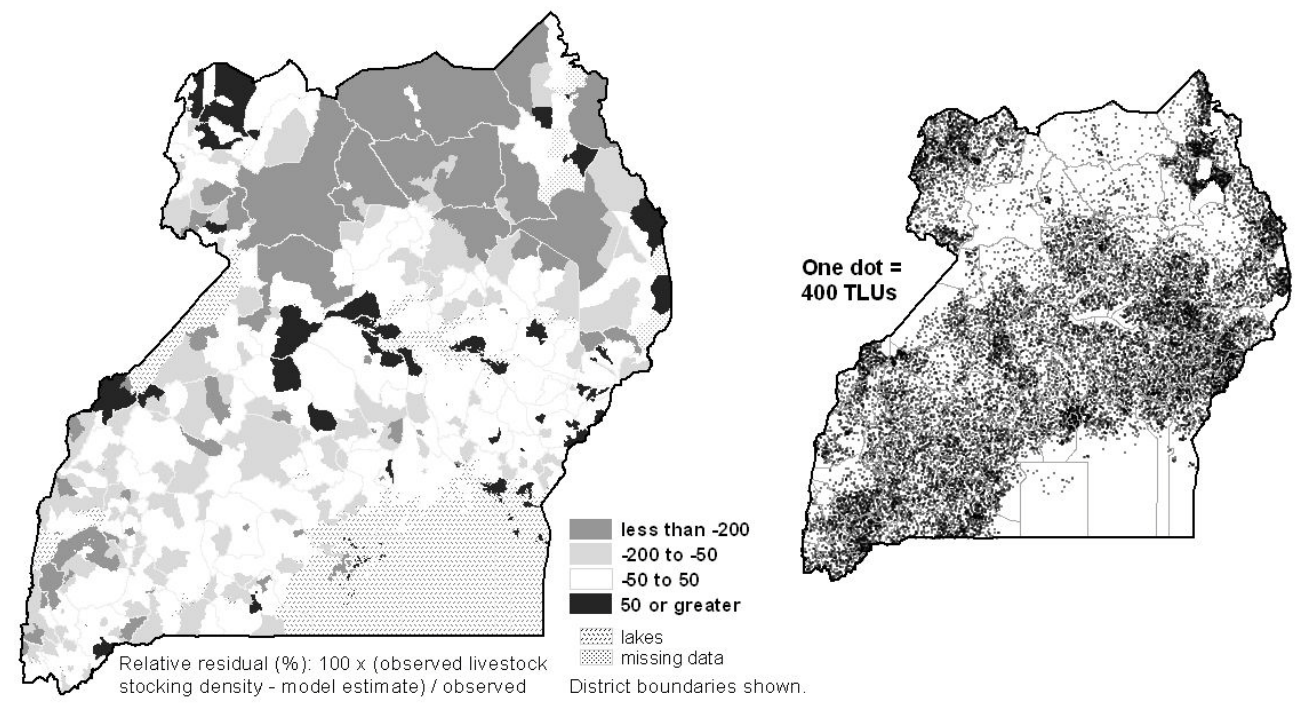

Positive relative residuals: On the basis of the statistical relationships of the model, sub-counties with strongly positive relative residuals may be experiencing higher livestock populations than are sustainable - they are overstocked relative to the livestock carrying capacity of the land. There are far fewer sub-counties with strongly positive relative residuals than with strongly negative. Of note are clusters of sub-counties in the northern West Nile area of the northwest, parts of Karamoja in the northeast, some densely populated sub-counties around Mount Elgon on the eastern border, scattered subcounties along the densely populated northern shore of Lake Victoria, a cluster in the middle of the cattle belt in Kiboga and Masindi districts, an erratic cluster of sub-counties in the districts bordering Lake Kyoga and its wetlands, and the lowlands of Bundibugyo district at the southern end of Lake Albert.

These strongly positive relative residuals provide an initial indication of areas of interest for undertaking interventions to support more sustainable livestock production systems. In those areas with high densities of both human and livestock populations, considerably more intensive livestock production systems, possibly based on the importation of livestock feed from surrounding districts and on zerograzing systems, would be merited. In the areas of the cattle belt experiencing significant livestock pressure, greater regulation of the use of common pastures may be required, possibly through strengthening local natural resource management institutions, both traditional and those established under local governments.

However, the evidence presented here, which indicates those areas of Uganda that may be experiencing overstocking of livestock, is insufficient alone to justify developing livestock development programs. More detailed field analyses to determine whether these data are an accurate reflection of livestock populations in these areas are required before determining whether some programmatic response is merited. 
Negative relative residuals: Sub-counties with strongly negative relative residuals may be characterized as being understocked relative to what should be expected given their characteristics of human population, agroecological conditions, and market access. If there are no local binding constraints on increasing livestock production, these areas should be candidates for accelerated efforts at livestock development, if the initial indications shown here are confirmed by field investigations.

Sub-counties with strongly negative residuals are certainly much more common than those with strongly positive residuals in Uganda, indicating considerable scope for increasing the national livestock herd and strengthening the livestock subsector of the economy. In examining the distribution of such subcounties, the simple dominant pattern is that they are principally found in northern Uganda, particularly the north central area. This is not surprising given the conflict between the government of Uganda and the Lord's Resistance Army (LRA) that characterized this area from the late 1980s until quite recently. Many people of this area were internally displaced, forced to leave their rural homesteads and dispossessed of any livestock they owned. It is only in the past two to three years that relative peace has returned to the area and households are returning to their homes and rebuilding their livelihoods. However, it will be some time before these returnees will be able to rebuild their aggregate livestock herd to a level that reflects the potential livestock carrying capacity of the area.

Outside the LRA-affected areas of northern Uganda, there are several other clusters where understocking of livestock may be evident. Some areas of Karamoja in the northeast and neighboring districts in the Teso area to the northeast of Lake Kyoga show negative relative residuals. This also may be a result of conflict, particularly recurrent cattle raiding, over the past two decades. The southern part of the West Nile area in the northwest similarly appears to have lower numbers of livestock than would otherwise be expected. This area also has not been immune from conflict in recent years, but there may be other local factors operating as well. In southwestern Uganda, there are scattered sub-counties with strongly negative relative residuals. Several of these contain significant protected areas - national parks or forest reserves - that restrict livestock production. Others will require closer study to determine whether there are local constraints that would limit the potential for increased livestock development. Moreover, the data quality issue that was highlighted in describing the positive relative residual spatial distribution also applies to the negative relative residuals pattern-for example, the extremely low numbers of livestock recorded in the 2008 National Livestock Census in districts in north central Uganda, as shown in the dot map in Figure 5, should be confirmed through fieldwork. 


\section{DISCUSSION}

In this paper we have demonstrated some of the value for development planning in the livestock sector in Uganda that can be derived from recently released data from the 2008 National Livestock Census. Subcounty-level estimates of livestock stocking densities were computed from the census and served as the dependent variable in order to model the statistical relationship between, on the one hand, population density, agroecological factors, and market access and, on the other hand, livestock numbers in an area. We then examined one of the elements related to the error in our resultant model, the residuals for each sub-county, to assess where in Uganda livestock stocking rates likely exceeded the carrying capacity of an area, and, conversely, where the numbers of livestock in an area appear to be far lower than could be sustained.

Several clusters across Uganda are judged in our analysis to be overstocked in terms of the livestock numbers that they should be supporting. In such areas, we suggest that livestock development activities focus on intensifying production systems, possibly based on zero-grazing systems and on developing markets for livestock feed and fodder imported from surrounding districts that have sufficient land for their production. In areas with more extensive livestock production systems that are experiencing overstocking, attention needs to be paid to strengthening the institutional mechanisms, both formal and informal, through which common pasture and other livestock-related resources are managed.

Much of the explanation for the low livestock stocking densities found in those areas of Uganda that our results indicate could have significantly larger livestock population lies in the history of conflict and the dislocation of rural households in these areas over the past 20 years. With peace returning to most of these areas, there is now the possibility of reconstituting livestock production systems. As such, livestock development should be a central element of the many efforts now underway in northern Uganda under the government's Peace, Recovery and Development Plan for Northern Uganda (PRDP). With appropriate support from the public sector and access to efficient input and output markets for livestock production, livestock owners in northern Uganda can make significant and enduring contributions to strengthening the livestock sub-sector of the economy of Uganda as a whole.

In sum, while this analysis is principally an exploration of the livestock census dataset, the results contribute to an agenda of action for future livestock development activities in Uganda. Our results demonstrate that there are many areas of the country where significant increases in livestock production are possible. Given that the majority of Ugandan households raise some livestock, public investment in the sub-sector is good for both broad economic growth and improved welfare at the level of the individual household. 


\section{REFERENCES}

Anderson, I.M., and W.I. Robinson. 2009. Tenth EDF Karamoja Livelihoods Program (KALIP) technical reference guide. Kampala: Food and Agriculture Organization of the United Nations and the Delegation of the European Commission to the Republic of Uganda.

Anselin, L. 1992. Spatial data analysis with GIS: An introduction to application in the social sciences. Technical report 92-10. National Center for Geographic Information and Analysis. Santa Barbara, Calif., U.S.A.: University of California, Santa Barbara.

Anselin, L., and S. Rey. 1991. The performance of tests for spatial dependence in linear regression. Technical report 91-13. National Center for Geographic Information and Analysis. Santa Barbara, Calif., U.S.A.: University of California, Santa Barbara.

Brown, D.G. 1996. Spatial statistics and GIS applied to internal migration in Rwanda, central Africa. In Practical handbook of spatial statistics, ed. S.L. Arlinghaus. Boca Raton, Fla., U.S.A.: CRC Press.

FAO (Food and Agriculture Organization of the United Nations). 2003. Africover Project. $<$ http://www.africover.org/>. Accessed 4 October 2005.

FAO (Food and Agriculture Organization of the United Nations). 2009. Programme Against African Trypanosomiasis. <http://www.fao.org/ag/againfo/programmes/en/paat/maps.html>. Accessed 23 September 2009.

Hijmans, R.J., S. Cameron, and J. Parra. 2005. WorldClim - Global Climate Data. $<$ http://www.worldclim.org/>. Accessed 9 September 2009.

Hooton, N., D. Lee-Smith, G. Nasinyama, and D. Romney. 2007. Championing urban farmers in Kampala: Influences on local policy change in Uganda. Research Report 2. Nairobi, Kenya: International Livestock Research Institute.

Jahnke, H.E., G. Tacher, P. Keil, and D. Rojat. 1988. Livestock production in tropical Africa with special reference to the tsetse-affected zone. In Livestock production in tsetse-affected areas of Africa. Proceedings of a meeting held by the International Livestock Centre for Africa (ILCA) and the International Laboratory for Research on Animal Diseases (ILRAD), November 23-27, 1987, in Nairobi, Kenya. Nairobi: ILCA/ILRAD.

Kennedy, P. 1985. A guide to econometrics. 2nd ed. Cambridge, Mass., U.S.A.: MIT Press.

Lee, J., and D.W.S. Wong. 2001. Spatial analysis with ArcView GIS. New York: John Wiley and Sons.

MAAIF (Ministry of Agriculture, Animal Industry and Fisheries) and UBOS (Uganda Bureau of Statistics). 2009. A summary report of the National Livestock Census, 2008. Entebbe, Uganda: MAAIF.

NPA (National Planning Authority, Uganda). 2010. National development plan (2010/11-2014/15). Kampala.

Robinson, A.H.; J.B. Lindberg, and L.W. Brinkman. 1961. A correlation and regression analysis applied to rural farm population densities in the Great Plains. Annals of the Association of American Geographers. 51 (2): 211-221.

Robinson, G., and K.J. Fairbairn. 1969. An application of trend-surface mapping to the distribution of residuals from a regression. Annals of the Association of American Geographers. 59 (1): 158-170.

Thomas, E.N. 1960. Maps of residuals from regression: Their characteristics and uses in geographic research. Department of Geography Report 2. Iowa City, Iowa, U.S.A.: University of Iowa. 


\section{RECENT IFPRI DISCUSSION PAPERS}

For earlier discussion papers, please go to http://www.ifpri.org/publications/results/taxonomy\%3A468. All discussion papers can be downloaded free of charge.

1007. Migratory responses to agricultural risk in northern Nigeria. Andrew Dillion, Valerie Mueller, and Sheu Salau. 2010.

1006. Do comprehensive Africa agriculture development program (CAADP) processes make a difference to country commitments to develop agriculture?: The case of Ghana. Shashidhara Kolavalli, Kathleen Flaherty, Ramatu Al-Hassan, and Kwaku Owusu Baah, 2010.

1005. The new Nicaraguan water law in context: Institutions and challenges for water management and governance. Paula Novo and Alberto Garrido , 2010.

1004. Potential of carbon markets for small farmers: A literature review. Alessandro De Pinto, Marilia Magalhaes, and Claudia Ringler, 2010.

1003. Understanding gender differences in agricultural productivity in Uganda and Nigeria. Amber Peterman, Agnes Quisumbing, Julia Behrman, and Ephraim Nkonya, 2010.

1002. Old problems in the new solutions? Politically motivated allocation of program benefits and the "new" fertilizer subsidies. Afua Branoah Banful, 2010.

1001. The role of public-private partnerships in promoting smallholder access to livestock markets in developing countries: methodology and case studies. Karl M. Rich and Clare A. Narrod, 2010.

1000. Mapping the policy process in Nigeria: Examining linkages between research and policy. Noora-Lisa Aberman, Eva Schiffer, Michael Johnson, and Victor Oboh, 2010.

999. Sales location and supply response among semisubsistence farmers in Benin: A heteroskedastic double selection model. Hiroyuki Takeshima and Alex Winter-Nelson, 2010.

998. A review of collective action in rural Ghana. Adam Salifu, Gian Nicola Francesconi, and Shashidhara Kolavalli, 2010.

997. Eight years of Doha trade talks: Where do we stand? Antoine Bouet and David Laborde Debucquet, 2010.

996. Price, inventories, and volatility in the global wheat Market. Kyösti Pietola, Xing Liu, and Miguel Robles, 2010.

995. Access, adoption, and diffusion: Understanding the long-term impacts of improved vegetable and fish technologies in Bangladesh. Neha Kumar and Agnes R. Quisumbing, 2010.

994. Economics of export taxation in a context of food crisis: A theoretical and CGE approach contribution. Antoine Bouët and David Laborde Debucquet, 2010.

993. What is the irrigation potential for Africa? A combined biophysical and socioeconomic approach. Liangzhi You, Claudia Ringler, Gerald Nelson, Ulrike Wood-Sichra, Richard Robertson, Stanley Wood, Zhe Guo, Tingju Zhu, and Yan Sun, 2010.

992. Impact of farmer field schools on agricultural productivity and poverty in East Africa. Kristin Davis, Ephraim Nkonya, Edward Kato, Daniel Ayalew Mekonnen, Martins Odendo, Richard Miiro, and Jackson Nkuba, 2010.

991. Exploring the long-term impact of development interventions within life-history narratives in rural Bangladesh. Peter Davis, 2010.

990. The costs and benefits of duty-free, quota-free market access for poor countries: Who and what matters? Antoine Bouët, David Laborde Debucquet, Elisa Dienesch, and Kimberly Elliot, 2010.

989. Mountains, global food prices, and food security in the developing world. Kamiljon T. Akramov, Bingxin Yu, and Shenggen Fan, 2010.

988. Examining the dynamic relationship between spot and future prices of agricultural commodities. Manuel Hernandez and Maximo Torero, 2010.

987. Dynamic agricultural supply response under economic transformation: A case study of Henan Province. Bingxin Yu, Fengwei Liu, and Liangzhi You, 2010. 



\section{INTERNATIONAL FOOD POLICY RESEARCH INSTITUTE}

www.ifpri.org

IFPRI HEADQUARTERS

$2033 \mathrm{~K}$ Street, NW

Washington, DC 20006-1002 USA

Tel.: +1-202-862-5600

Fax: +1-202-467-4439

Email: ifpri@cgiar.org

IFPRI ADDIS ABABA

P. O. Box 5689

Addis Ababa, Ethiopia

Tel.: +251116463215

Fax: +251116462927

Email: ifpri-addisababa@cgiar.org

IFPRI NEW DELHI

CG Block, NASC Complex, PUSA

New Delhi 110-012 India

Tel.: 9111 2584-6565

Fax: 9111 2584-8008 / 2584-6572

Email: ifpri-newdelhi@cgiar.org 